\title{
Design and Performance of an In-Line Surface- Induced Dissociation Device in a Four-Sector Mass Spectrometer
}

\author{
Kevin L. Schey, David A. Durkin, and Kelly R. Thornburg* \\ Department of Cell and Molecular Pharmacology and Experimental Therapeutics, Medical University of \\ South Carolina, Charleston, South Carolina, USA
}

A new in-line surface-induced dissociation device has been designed and characterized in a high performance four-sector tandem mass spectrometer. The design incorporates a target electrode parallel to the ion beam axis and an angled deflector plate $\left(45^{\circ}\right.$ relative to the ion beam) to provide large collision angles. In addition, an extraction electrode (parallel to the target electrode) is employed to efficiently extract product ions from the target surface. Results obtained with this device indicate high internal energy deposition (up to $16.3 \mathrm{eV}$ ) as measured with the thermometer ions $W(C O)_{6}^{+\cdot}$ and $\mathrm{Si}_{2}\left(\mathrm{C}_{2} \mathrm{H}_{5}\right)_{4}^{+}$, as evidenced by extensive dissociation of the refractory pyrene molecular ion, and as indicated by the $b_{3} / y_{2}$ ratio in the product ion spectrum of leucine enkephalin. High resolution provided by the four-sector instrument for both precursor ions and product ions allows the observation of previously unobserved dissociation products in the surface-induced dissociation spectra of $\mathrm{Si}\left(\mathrm{C}_{2} \mathrm{H}_{5}\right)_{4}^{+}$. and novel ion-surface reaction products in spectra of $\mathrm{W}(\mathrm{CO})_{6}^{+\cdot}$ ions after collisions with hydrocarbon-covered surfaces. Both hydrogen atom and hydrocarbon abstraction products are observed. The dissociation efficiencies measured with the in-line device are approximately $1 \%$ when hydrocarbon-coated surfaces are used and increase fivefold with a fluorinated surface. (J Am Soc Mass Spectrom 1995, 6, 257-263)

$\mathrm{P}$ olyatomic ion-surface collisions now are being utilized by a number of investigators to study ion dissociation [surface-induced dissociation (SID)] and/or ion-surface reactions [1,2]. The advantages of SID for ion dissociation studies include high internal energy deposition [3], fine control of internal energy deposition [4], and potentially high dissociation efficiencies [5]. Furthermore, the ion-surface collision products of several projectile ions have been reported to be sensitive to surface adsorbates, which provides the potential for surface analysis capabilities [6-8]. It is clear that the nature of the surface plays an important role in low energy ion-surface interactions. For example, surface effects have been reported to include effects on energy deposition and on dissociation efficiencies, as well as on ion-surface reactions [9-12]. The unique capabilities afforded by the use of low energy ion-surface collisions have led to a number of studies that range from fundamental ion-surface chemistry [6, 13-15] and isomer differentiation [16] to applications in peptide sequencing $[17-20]$ and cluster chemistry $[21,22]$.

Address reprint requests to Dr. Kevin L. Schey, Department of Cell and Molecular Pharmacology, 171 Ashley Avenue, Medical University of South Carolina, Charleston, SC 29425.

*Present address: Hauser Chemical Research, Inc., 5555 Airport Boulevard, Boulder, CO 80301.
Ion-surface collisions have been carried out in several types of mass spectrometers with little or no hardware modification, for example, in Fourier transform mass spectrometry (FTMS) instruments [23, 24], reflector time-of-flight instruments [21], or quadrupole ion trap devices [25]. However, obstacles still remain to the routine application of this experiment in "beam" instruments such as sector, quadrupole, and hybrid instruments. These instruments, with few exceptions, have required custom configuration of the mass analyzers to accommodate SID. Several in-line devices have been reported [26, 27] for use in tandem quadrupole or hybrid instruments and even sector instruments [28, 29]. Recently, two simple devices for utilizing ion-surface collisions in four-sector mass spectrometers were described [30-32]. We report here on the performance of a new in-line device for use in a high performance four-sector mass spectrometer that can be modified for use in all beam-type tandem instruments. The design of this device allows rapid conversion from conventional collision-activated dissociation (CAD) to the SID experiment and provides high quality SID data with dissociation efficiencies similar to custom SID instruments.

The advantages of the use of a high performance instrument for SID include high resolution of both precursor and product ions, a well-focused precursor ion beam that facilitates manipulation of the ion beam 
and evaluation of the performance of the device, a larger available mass range than quadrupole instruments, which allows examination of high mass ion dissociation, and access to the high collision energy regime. The advantages of SID, in contrast to high energy $C A D$, in a high performance instrument include potentially high dissociation efficiencies, high average internal energy deposition, and sensitive control of the internal energy deposited. This combination of instrument and collision cell could be important in efforts to improve detection limits over high energy CAD experiments and in efforts to fragment larger molecules. As currently practiced, high energy CAD detection limits are limited by poor CAD ion yields (less than $10 \%$ of the main beam intensity recorded as product ions [33]). The mass limit of approximately $2500 \mathrm{u}$ to generate fragmentation via high energy CAD [33] is presumed to be due to the inability to deposit large internal energies in the instrumental time scale. We report here our design of a prototype in-line SID device and the initial results obtained with the device placed in a JEOL (Peabody, MA) HX110/HX110 tandem mass spectrometer.

\section{Experimental}

The SID experiments were carried out in a JEOL HX110/HX110 tandem mass spectrometer with an EBEB geometry. Typical operating resolution of MS-1 and MS-2 was 1500, which allows the selection of an isotopically pure precursor ion and better than unit resolution in product ion spectra for the relatively small molecules examined here. Electron impact ionization was carried out on volatile liquids introduced through the inlet reservoir or on volatile solids via a direct insertion probe. Peptide samples were ionized by liquid secondary ionization mass spectrometry (LSIMS) ionization that employed $15-\mathrm{keV} \mathrm{Cs}^{+}$ion bombardment. Peptide samples (typically $1-3 \mathrm{nmol}$ in deionized water) were mixed $(1 / 1, v / v)$ in a glycerol matrix. A B/E linked scan was used to scan MS-2 to record product ion spectra at rates of 60 or $120 \mathrm{~s} /$ $6000 \mathrm{u}$. JEOL Complement ${ }^{\text {(8) }}$ software was used to calculate and implement MS-2 linked scan parameters for floating collision cell operation with the SID target surface (collision cell voltage) that ranged from 9.30 to $9.95 \mathrm{kV}$. Simple MS-2 magnet scans also were used to detect ion-surface reaction products that appear at masses above that of the precursor ion. Typically 5-10 scans were summed to produce a product ion spectrum.

Nonpeptide samples were purchased from Aldrich Chemical Company (Milwaukee, WI) and used without further purification. Leucine enkephalin was purchased from Sigma Chemical Company (St. Louis, MO) and used without further purification.

The target surface was cleaned with methanol and acetone prior to insertion of the device into the instru- ment. Surface modification experiments with the perfluoropolyether Krytox-1625 [34] (DuPont Corp., Wilmington, DE) were carried out by placing one drop $(10 \mu \mathrm{L})$ of liquid on the target surface, spreading to cover the entire surface, and wiping away excess fluid. The collision region is pumped by three diffusion pumps that have a combined pumping speed of 817 $\mathrm{L} / \mathrm{s}$, which provides a pressure below $1 \times 10^{-6}$ torr (the limit of our ion gauge).

Internal energy deposition was determined by the method of Wysocki et al. [35]. Known activation energies for sequential fragmentations of thermometer molecules such as $\mathrm{Si}\left(\mathrm{C}_{2} \mathrm{H}_{5}\right)_{4}^{+\cdot}$ and $\mathrm{W}(\mathrm{CO})_{6}^{+\cdot}$ are used in combination with the abundance of these fragments in the product ion spectra to generate internal energy distribution curves. These curves are calculated for each collision energy and subsequently a weighted average internal energy deposited is determined.

\section{Results and Discussion}

\section{Device Design}

The design of the in-line device is shown in Figure 1. The device is similar to the slant plate design of Wysocki et al. [27], but it has been modified to include a tail electrode and a deceleration-acceleration lens system similar to the JEOL CAD collision cell. The electrodes of the SID device were made of brass sheet stock (0.025-in. thickness). The Kel-F (AIN Plastics, Norfolk, VA) mounting base was machined identically to the JEOL collision cell mount to provide fast exchange of collision cells. Grooves ( 0.028 in. wide) were machined every 0.125 in. into the top surface of the mounting base for insertion of the lens elements. This produced a space between each element of the target lens and extraction lens of $8.85 \mathrm{~mm}$. The grooves provide for easy repositioning of the electrodes in the initial stage of geometry optimization. The typical time to change between CAD and SID devices is $15 \mathrm{~min}$ plus the appropriate pump down time.

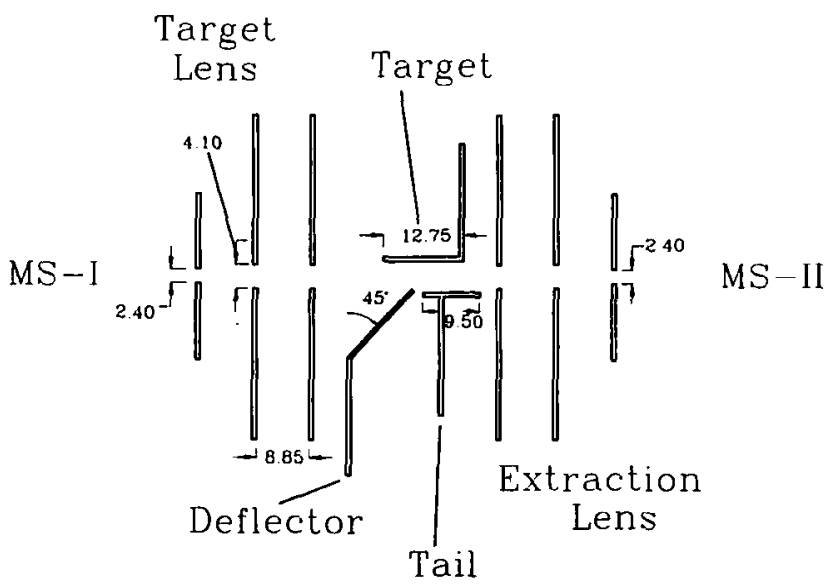

Figure 1. Top view of the electrode positions for the in-line SID device. All dimensions are in millimeters. 
Previously reported in-line devices $[26,27]$ provided minimal extraction fields for extraction of product ions because the tail electrode was held at the same voltage as the deflector. The simple design of Despeyroux et al. [31] employs three electrodes parallel to the target surface: one for deflection of precursor ions, a second for extraction of product ions, and a third "guard" electrode. In our design we provide a deflector plate positioned $45^{\circ}$ to the ion beam and an electrically isolated tail electrode positioned parallel to the target surface. The electric field generated by the angled deflector is postulated to cause a higher collision angle than a parallel deflector plate would and therefore potentially higher internal energy deposition. The tail electrode is predicted to provide an extraction field for acceleration of product ions away from the target surface and additionally to provide some steering fields for proper focusing into the entrance slit of the MS-2 of the JEOL instrument. SIMION [36] ion trajectory calculations provide evidence that, indeed, the isolated tail electrode allows for more efficient ion manipulation compared to previously reported designs.

A series of SIMION calculations were carried out by using experimentally determined electrode voltages to produce SID signals. The SIMION trajectory shown in Figure 2a indicates that ions that enter the collision region, having a beam width of $2 \mathrm{~mm}$ and translational energies of $10 \mathrm{keV}$, are adequately delivered to the SID target surface for $100-\mathrm{eV}$ collisions. Subsequently, product ions that leave the target surface with an angle (exit angle) of $29^{\circ}$ with respect to the target surface and kinetic energies of $20 \mathrm{eV}$ are efficiently extracted and focused into MS-2. These calculations predict that specific spatial, angular, and energetic requirements must be met for successful extraction of product ions from the target surface. For example, the product ions formed closer to MS-2 are extracted more easily and therefore have lower kinetic energy and exit angle requirements. Product ions formed closer to MS-1 (where, in Figure 2, precursor ions are predicted to collide with the target) require larger kinetic energies and/or larger exit angles to be extracted into MS-2. The enlarged target region shown in Figure $2 b$ shows more clearly the collision angles and positions of precursor ions that strike the target surface as a function of their initial position entering the collision cell. The precursor ion collision angles are plotted as a function of collision position in Figure 3 for an angled $\left(45^{\circ}\right)$ deflector plate and for a deflector plate positioned parallel to the target surface. It is clear that the angled deflector provides a higher collision angle at a given position on the target surface than the parallel deflector. However, the magnitude of this effect is not large and may not produce experimentally observable effects in the SID experiment. Deflector angle effects are currently under experimental examination. SIMION calculations also were carried out on the same geometry without the tail electrode (data not shown). These
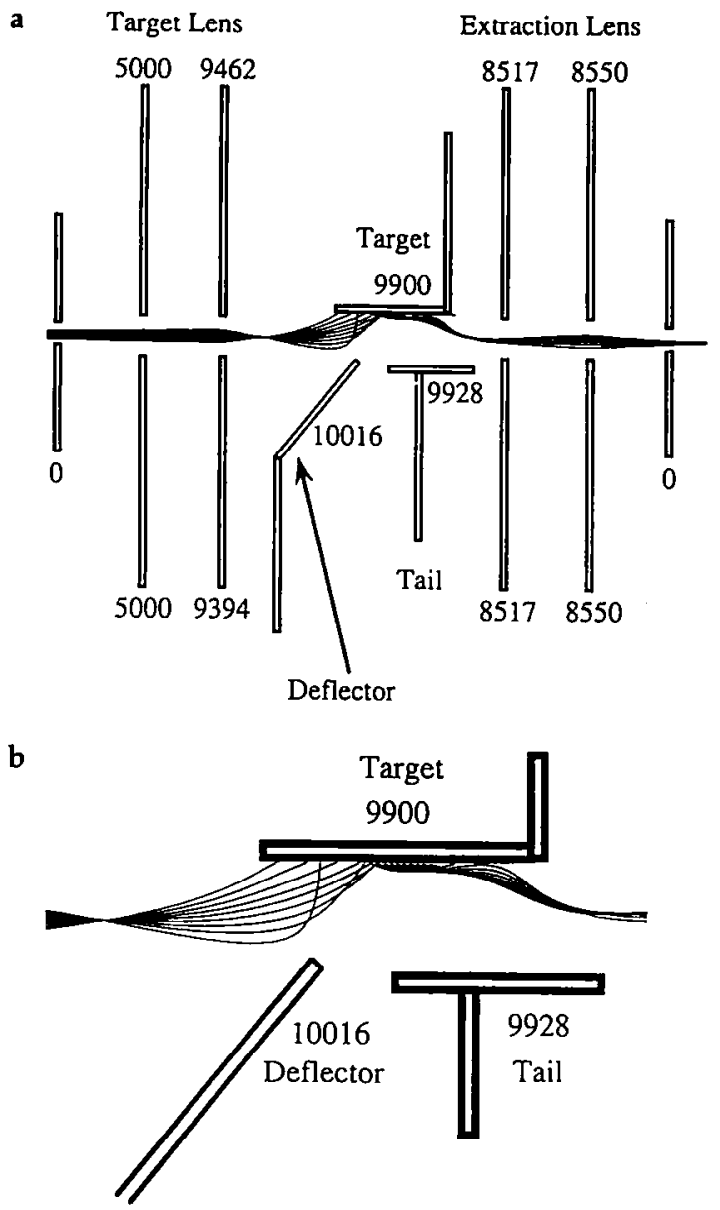

Figure 2. (a) SIMION ion trajectory calculations for $100-\mathrm{eV}$ ion-surface collisions. Calculations for precursor ions that enter the target lens are superimposed with calculations for product ions extracted from the target surface. Initial precursor ion beam conditions are $10-\mathrm{keV}$ kinetic energy and a $2-\mathrm{mm}$ beam width. Initial product ion conditions are $29^{\circ}$ exit angle and $20-\mathrm{eV}$ kinetic energy. (b) Enlarged target region that shows collision and extraction angles and positions.

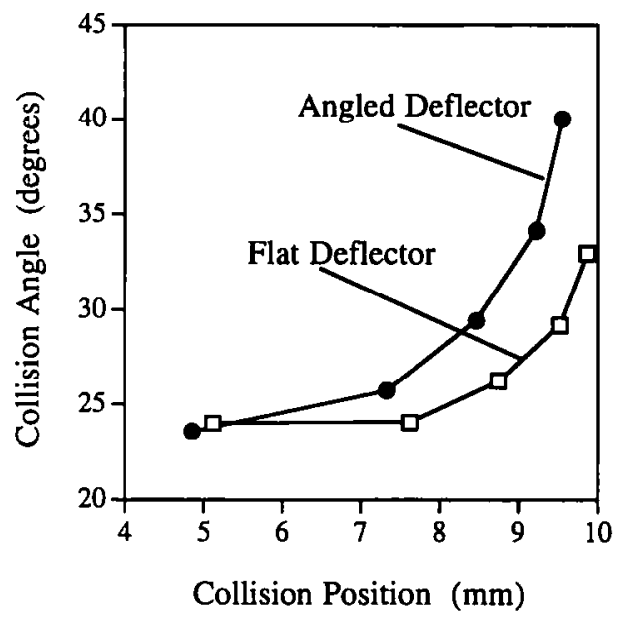

Figure 3. Precursor ion collision angles as a function of collision position for $45^{\circ}$ deflector ( $)$ and $180^{\circ}$ (parallel to target surface) deflector $(\square)$. The collision position indicated is from the front edge of the target electrode (in millimeters). 
simulations indicate that product ion extraction and focus into MS-2 were severely hindered in the absence of the tail electrode. Subsequent experiments verified this prediction in that very poor product ion currents were obtained without the tail electrode.

\section{Experimental Results}

The average internal energy deposited in low energy ion-surface collisions has been reported to vary with laboratory collision energy up to $14 \mathrm{eV}$ by using the $\mathrm{Si}\left(\mathrm{C}_{2} \mathrm{H}_{5}\right)_{4}^{+\cdot}$ thermometer ion in a $90^{\circ}$ SID instrument [37] and up to $10.5 \mathrm{eV}$ by using the $\mathrm{W}(\mathrm{CO})_{6}^{+\cdot}$ thermometer ion in an in-line SID instrument [26]. We used the $\mathrm{W}(\mathrm{CO})_{6}^{+\cdot}$ ion to determine the average internal energy deposition as a function of collision energy with the in-line SID device described here. By using this device the average internal energy deposited varies with collision energy up to $14 \mathrm{eV}$ as shown in Figure 4. Interestingly, a clear difference in internal energy deposition is observed between the fluorinated surface and surfaces that have not been specially prepared and that are believed to be coated with hydrocarbons from residual pump oil. The differences are particularly clear at lower collision energies. Similar effects have been reported previously as indicated by changes in product ion distributions with different surfaces [9-12].

The plateau in the internal energy deposition curve that starts at $300-\mathrm{eV}$ collision energy is caused by the inability to fragment $\mathrm{W}(\mathrm{CO})_{6}^{+\cdot}$ beyond the $\mathrm{W}^{+\cdot}$ ion and not by a true plateau in the internal energy deposition function. A similar plateau that starts at a collision energy of $200 \mathrm{eV}$ was measured qualitatively, by using product ion ratios, with an in-line device by Despeyroux et al. [31]. Evidence for increased internal energy deposition beyond $14 \mathrm{eV}$ exists in the data where the pyrene molecular ion continues to dissociate to smaller product ions as the collision energy in-

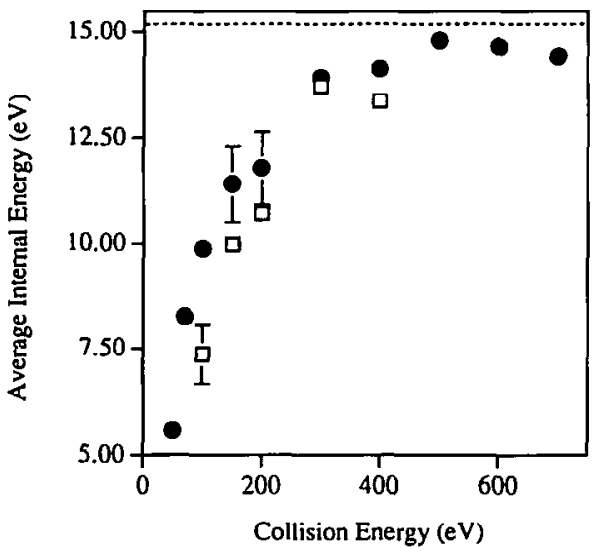

Figure 4. Average internal energy deposited into $\mathrm{W}(\mathrm{CO})_{6}^{+\cdot}$ ions by ion-surface collisions in the in-line device as a function of laboratory frame collision energy by using a fluorinated surface $(C)$ and a hydrocarbon surface ( $\square$ ). The dashed line at $15.2 \mathrm{eV}$ represents the average internal energy assigned to $\mathrm{W}^{+\cdot}$ ions. creases beyond $400 \mathrm{eV}$ and the appearance of the $\mathrm{SiH}^{+}$ ion in the product ion spectrum of $\mathrm{Si}\left(\mathrm{C}_{2} \mathrm{H}_{5}\right)_{4}^{+}$, which requires $16.3 \mathrm{eV}$ of internal energy. Although the internal energy distributions are not shown, they are nearly identical to previously reported narrow SID distributions with widths of $4-5 \mathrm{eV}$ (full width at half maximum). The maximum efficiency obtained for conversion of translational energy to internal energy was $9.5 \%$ in $100-\mathrm{eV}$ collisions with the fluorinated surface. This value is slightly lower than the $13 \%$ reported by Bier et al. [26] with their in-line device and lower than the 18 and $19 \%$ reported for fluorinated surfaces in a $90^{\circ}$ instrument $[12,34]$. This lower efficiency compared to $90^{\circ}$ devices may be due to glancing collisions with the target surface in the in-line devices.

Further evidence of high internal energy deposition and instrument performance is provided in Figure 5, which is a 200-eV SID spectrum of pyrene. The [M $2 \mathrm{H}]^{+}, m / z 200$, is the most abundant product ion and extensive fragmentation is observed in this spectrum. As has been previously described [38], product ions that correspond to the formulae $\mathrm{C}_{n} \mathrm{H}_{2}^{+\cdot}$ and $\mathrm{C}_{n} \mathrm{H}_{3}^{+}$are observed, where $n=2-12$. In addition, product ions in the series $\mathrm{C}_{n} \mathrm{H}_{6}^{+\cdot}$ and $\mathrm{C}_{n} \mathrm{H}_{7}^{+}$also are observed from $n=10-15$. These two product ion series, predicted to be linear $\left(\mathrm{C}_{n} \mathrm{H}_{2}^{+\cdot}\right.$ and $\mathrm{C}_{n} \mathrm{H}_{3}^{+}$ions $)$and cyclic $\left(\mathrm{C}_{n} \mathrm{H}_{6}^{+\cdot}\right.$ and $\mathrm{C}_{n} \mathrm{H}_{7}^{+}$ions), overlap in the region of $m / z$ 122-130, where a broad distribution of product ions is observed. The high resolution obtainable with the JEOL instrument is displayed by the fact that every peak in this spectrum is clearly resolved from peaks that are $1-u$ distant. This resolution can enhance the ability to determine product ion structures.

The resolution obtainable with the JEOL instrument has not only improved product ion structure determination, but also has allowed the observation of previously unobserved ion-surface phenomena. In dissociative collisions of $\mathrm{Si}\left(\mathrm{C}_{2} \mathrm{H}_{5}\right)_{4}^{+*}$, an internal energy

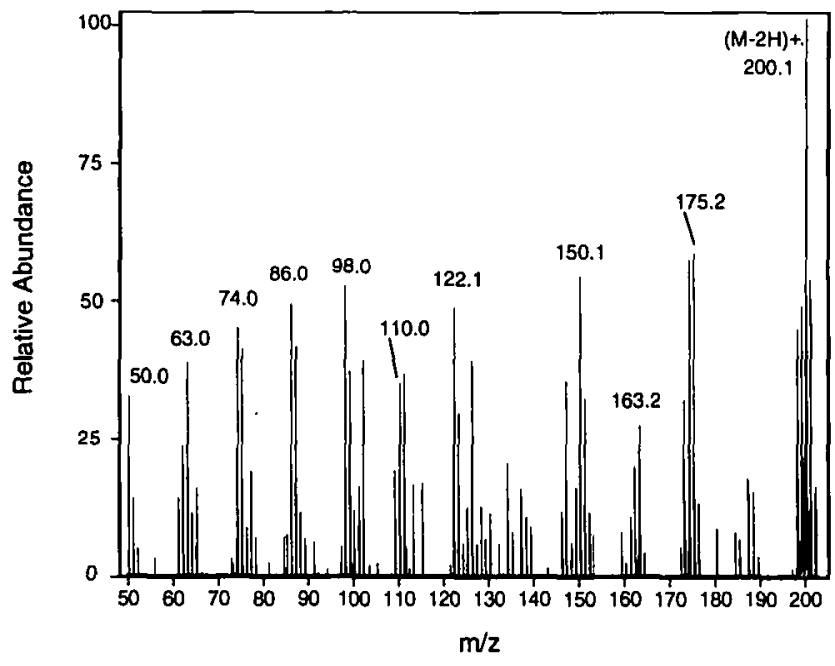

Figure 5. 200-eV SID spectrum of the pyrene molecular ion, $m / z 202$, with a hydrocarbon surface. 
thermometer ion, the $\mathrm{SiH}^{+}$ion intensity at $m / z 29$ can be used in internal energy calculations (activation energy, $16.3 \mathrm{eV}$ [39]). The 500-eV SID spectrum of $\mathrm{Si}\left(\mathrm{C}_{2} \mathrm{H}_{5}\right)_{4}^{+\cdot}$ shown in Figure 6 indicates two ions clearly resolved at nominal mass 29. The ions have been assigned to the two structures $\mathrm{SiH}^{+}$and $\mathrm{C}_{2} \mathrm{H}_{5}^{+}$, which differ by $0.06 \mathrm{u}$. (The inaccuracies of the reported masses are due to the instrument calibration, which is based on CsI clusters of $m / z 133$ and higher). By using a fluorinated surface where sputtering of surface adsorbates is inhibited, the peak assigned to $\mathrm{C}_{2} \mathrm{H}_{5}^{+}$decreases to $30 \%$ of its original intensity, which indicates that roughly two thirds of the $\mathrm{C}_{2} \mathrm{H}_{5}^{+}$ion current originates from hydrocarbons on the target surface whereas the remaining one third originates from the precursor ion. The intensity at $\mathrm{m} / z 29$ from $\mathrm{C}_{2} \mathrm{H}_{5}^{+}$would contribute to errors in internal energy calculations, which rely on the relative abundance of the high energy $\mathrm{SiH}^{+}$ ion, but which utilize the intensity of the unresolved $m / z 29$ in the determinations.

The high resolution of the JEOL instrument also has allowed the novel observation of hydrogen atom and hydrocarbon pickup from the surface in ion-surface collisions of $\mathrm{W}(\mathrm{CO})_{\mathrm{h}}^{+\cdot}$ ions on a hydrocarbon-covered surface. Although it has been reported previously [12, 34] that $\mathrm{W}(\mathrm{CO})_{6}^{+\cdot}$ ions, upon collision with a fluorinated surface, abstract up to five fluorine atoms, the resolution of these experiments was not sufficient to separate product ions from product ions that have abstracted hydrogen atoms. As shown in Figure 7a, hydrogen atom abstraction can be observed for all product ions in the $150-\mathrm{eV}$ SID spectrum of $\mathrm{W}(\mathrm{CO})_{6}^{+*}$, $m / z 350$ (which contains ${ }^{182} \mathrm{~W}^{12} \mathrm{C}^{16} \mathrm{O}$ only, as selected by MS-1), in collisions with a hydrocarbon-covered surface. When a fluorinated surface is utilized, hydrogen atom abstraction disappears and fluorine atom abstraction is observed as shown in Figure $7 \mathrm{~b}$ for $200-\mathrm{eV}$ collisions. In addition to hydrogen atom ab-

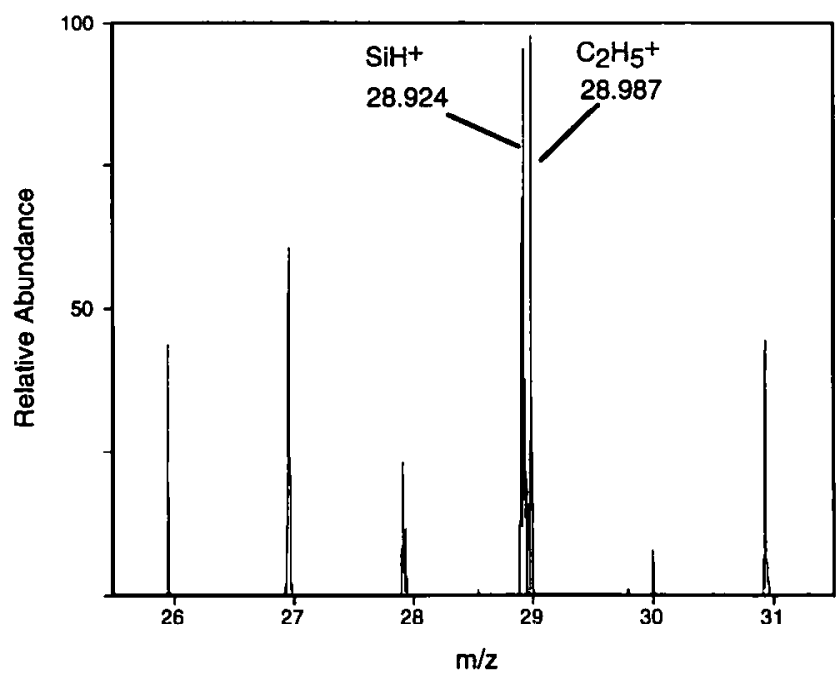

Figure 6. 500-eV SID spectrum of $\mathrm{Si}\left(\mathrm{C}_{2} \mathrm{H}_{5}\right)_{4}^{+} ; m / z 144$, in the range of $m / z 26-31$ with a hydrocarbon surface.
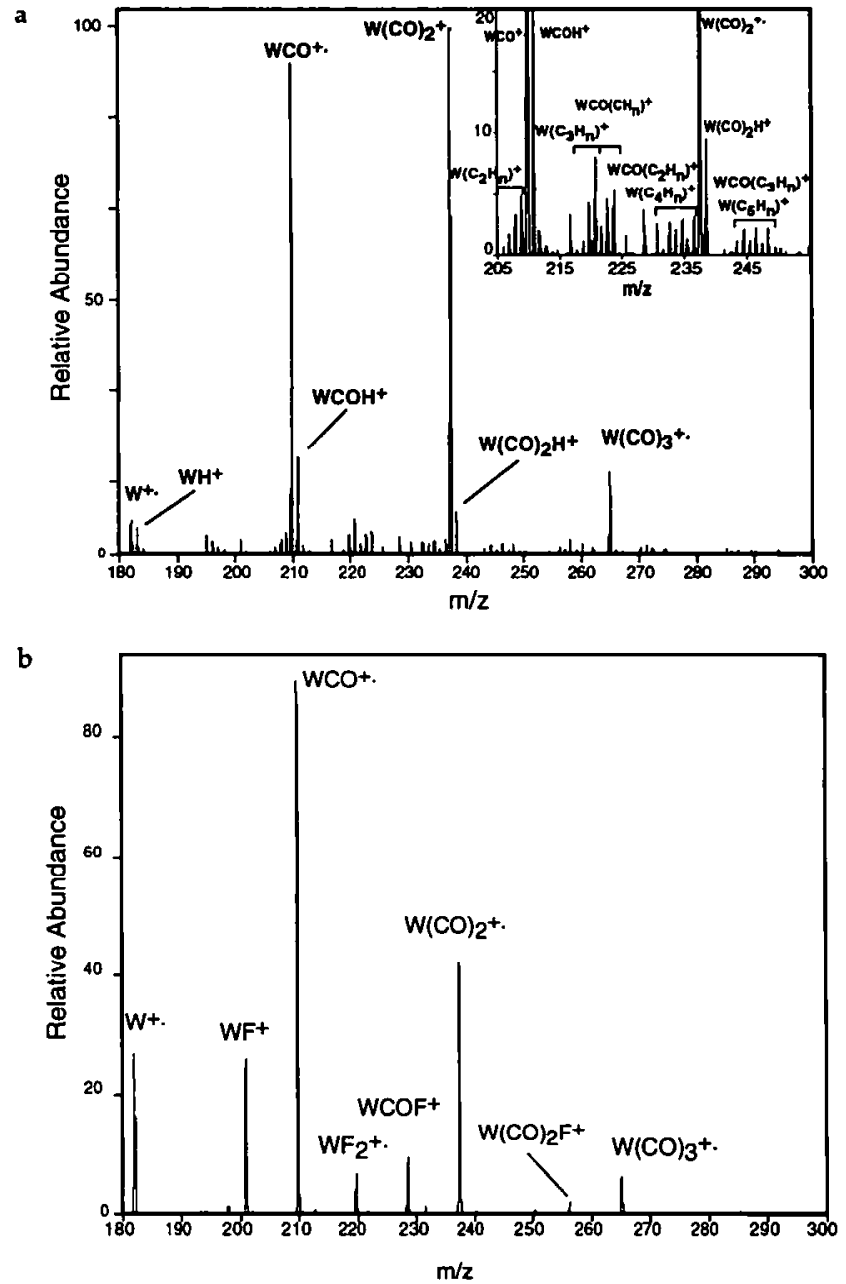

Figure 7. (a) 150 -eV SID spectrum of $\mathrm{W}(\mathrm{CO})_{6}^{+*}, m / z 350$, with a hydrocarbon surface and (b) $200-\mathrm{eV}$ SID spectrum with a fluorinated surface.

straction, hydrocarbon abstraction also is observed in collisions with a hydrocarbon-covered surface as indicated in the insert in Figure 7a. This ion-surface reaction has been observed previously for benzene and for polycyclic aromatic hydrocarbons such as naphthalene, anthracene, and pyrene [7, 14]; however, it has not been reported for the $\mathrm{W}(\mathrm{CO})_{6}^{+\cdot}$ ion. Extensive reaction products are observed in the form of alkyl pickup with subsequent hydrogen atom losses. Although it is difficult to assign unambiguous structures to each product ion observed, for example, the product ion at $\mathrm{m} / \mathrm{z}$ 223 could be either $\left[\mathrm{W}+\mathrm{C}_{3} \mathrm{H}_{5}\right]^{+}$or $[\mathrm{WCO}+\mathrm{CH}]^{+}$, it is clear that large hydrocarbons or multiple hydrocarbon species are abstracted from the surface. For example, the product ion at $m / z 244$ can be assigned only to $\mathrm{WC}_{5} \mathrm{H}_{2}^{+*}$, which indicates that either pentyl groups are abstracted from the surface or that multiple hydrocarbon abstractions occur. Note that the ion-surface reaction products of significant intensity ( $>1 \%$ relative abundance) and that could be assigned structures were used in the internal energy calculations. 
An example of peptide ion-surface collision data is shown in Figure 8 for the often studied pentapeptide leucine enkephalin. At a collision energy of $60 \mathrm{eV}$ and with a hydrocarbon-coated surface, the SID spectrum for this peptide shows mainly $a, b$, and $y$ sequence ions [40] and seems more typical of low rather than high energy CAD. However, evidence of high energy $d$ and $w$ ions in peptide SID spectra has been reported [17]. We also have seen evidence of $d$ and $w$ ions for larger peptide ions. Jackson et al. [41] examined leucine enkephalin with their in-line device and reported similar ion types; however, a much broader distribution of product ions at a higher collision energy of $200 \mathrm{eV}$ was observed. At this collision energy, by using the in-line device described here, the leucine enkephalin data collapses to predominantly immonium ions.

An interesting feature of the leucine enkephalin data is the doublet at $m / z 278,279$ ( $b_{3}, y_{2}$ ions), which is clearly resolved in this spectrum as shown in the insert. Resolution of this doublet of important sequence ions has not been demonstrated with other SID instruments. Furthermore, the ratio of $278 / 279$ has been shown by Alexander and Boyd [42] to be indicative of internal energy deposition. Their data indicate that under mildly energetic conditions (low collision gas pressures or low collision energies, $<30 \mathrm{eV}) \mathrm{m} / \mathrm{z}$ 279 predominates, whereas under more energetic conditions (multiple collision conditions or higher collision energies, $>30 \mathrm{eV}$ ) the ratio of $\mathrm{m} / z 278 / 279$ approaches 2 . The ratio observed in the SID spectrum shown in Figure 8 is similar to that observed under the most energetic conditions examined by Alexander and Boyd, which indicates high internal energy deposition into this peptide ion.

The efficiency of dissociation has been measured for the molecular ions of benzene and $\mathrm{W}(\mathrm{CO})_{6}$. The measurement involves deflection of precursor ions past the target (avoiding collision) and measurement of the ion signal followed by adjustment of the electrode potentials to optimize SID signals and summation of the

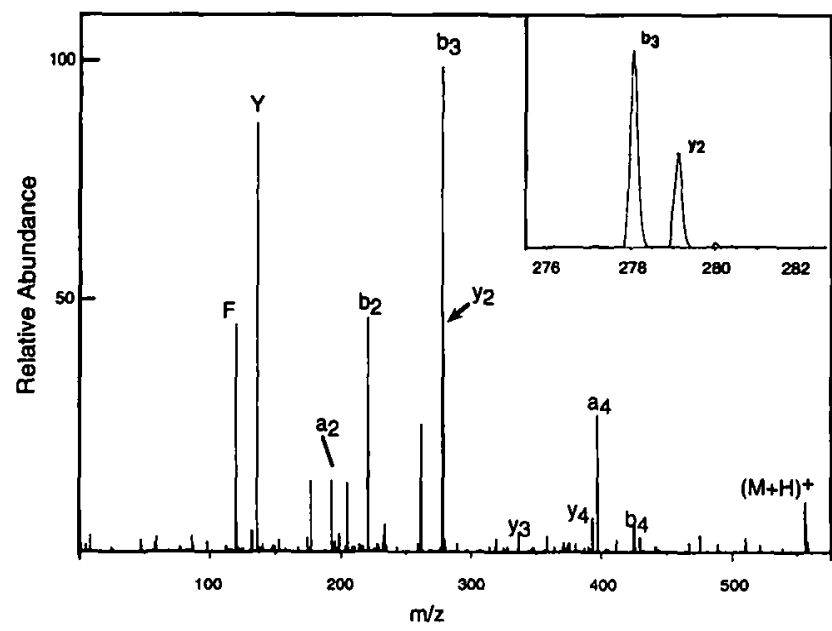

Figure 8. 60-eV SID spectrum of leucine enkephalin $[\mathrm{M}+\mathrm{H}]^{+}$ ion, $m / z 556$, with a hydrocarbon surface. product ion signals. Therefore the definition of dissociation efficiency used here is

$$
\begin{aligned}
& \text { dissociation efficiency } \\
& \quad=\sum \text { (product ions) } / \sum \text { (precursor ions) }
\end{aligned}
$$

Measured SID dissociation efficiencies are $0.75 \%$ for benzene and $1.25 \%$ for $\mathrm{W}(\mathrm{CO})_{6}$ in $100-\mathrm{eV}$ collisions with a hydrocarbon covered surface. The efficiencies improve by fivefold when the Krytox-coated surface is used for both benzene $(3.67 \%)$ and $W(C O)_{6}(6.51 \%)$. The efficiency value measured for the collision of the benzene radical cation with a hydrocarbon surface is slightly higher than that reported by Wysocki et al. [27] with an in-line device and is more similar to the value they report for a $90^{\circ} \mathrm{SID}$ experiment. Morris et al. [12] reported a similar three- to ten-fold increase in dissociation efficiencies by using a fluorinated surface compared to hydrocarbon surfaces.

A serious difficulty in these experiments is the deceleration required to carry out low energy collisions in a high energy instrument. Currently deceleration occurs in the target lens of the device, which is empirically optimized for maximum ion signals. A potential improvement in ion transmission is the addition of an einzel lens prior to the deceleration region as reported by $\mathrm{Yu}$ and Martin [43] for this same instrument. High transmissions have been achieved with this design and we will evaluate such a device in our instrument in the near future.

\section{Conclusions}

The in-line device described here in combination with the JEOL four-sector instrument provides high quality SID data. The SID data are similar to those reported for other SID devices in regard to internal energy deposition, ion-surface reactive collisions, and peptide fragmentation. However, the JEOL instrument provides superior resolution, which allows the observation of novel ion-surface collision phenomena. This combination of dissociation device and mass analyzer provides a powerful tool for ion structure determination in that high resolution, high internal energy deposition, and fine control of internal energy deposition are available. Surface modifications have produced dissociation efficiencies that approach those available in high energy CAD experiments.

\section{Acknowledgments}

This work was supported by an ASMS research award to KLS, MUSC Institutional Research Funds, and NSF grant DIR 8804502. The authors also acknowledge Cliff Harvey for his expert machining. The authors wish to thank Dr. Daniel Knapp for his helpful comments on the manuscript.

\section{References}

1. Mabud, Md. A.; Dekrey, M. J.; Cooks, R. G. Int. J. Mass Spectrom. Ion Processes 1985, 67, 285-294. 
2. Cooks, R. G., Ast, T.; Mabud, Md. A. Int. J. Mass Spectrom. Ion Processes 1990, 100, 209-265.

3. Dekrey, M. J.; Kenttamaa, H. I.; Wysocki, V. H.; Cooks, R. G. Org. Mass Spectrom. 1986, 21, 193-195.

4. Vincenti, M.; Cooks, R. G. Org. Mass Spctrom. 1988, 23, 317-322.

5. Williams, E. R.; Fang, L.; Zare, R. N. Int. I. Mass Spectrom. Ion Processes 1993, 123, 233-241.

6. Riederer, D. E.; Miller, S. A.; Ast, T.; Cooks, R. G. J. Am. Soc. Mass Spectrom. 1993, 4, 938-942.

7. Williams, E. R.; Jones, G. C.; Fang, L.; Zare, R. N.; Garrison, B. J.; Brenner, D. W. J. Aml. Chem. Soc. 1992, 114, 3207-3210.

8. Kane, T. E.; Somogyi, A.; Wysocki, V. H. Org. Mass Spectrom. 1993, 28, 1665-1673.

9. Winger, B. E.; Julian, R. K.; Cooks, R. G. J. Am. Chem. Soc. 1991, 113, 8967-8969.

10. Wysocki, V. H.; Jones, J. L.; Ding, J.-M. J. Am. Chem. Soc. 1991, 113, 8969-8970.

11. Ast, T.; Schey, K. L.; Cooks, R. G. I. Serb. Chem. Soc. 1990, 55 , 247-256.

12. Morris, M. E.; Riederer, D. E.; Winger, B. E.; Cooks, R. G.; Ast, T.; Chidsey, C. E. D. Int. I. Mass Spectrom. Ion Processes 1992, 122, 181-217.

13. Pradeep, T.; Riederer, D. E.; Ast, T.; Cooks, R. G. Rapid Commum. Mass Spectrom. 1993, 7, 711-713.

14. Ast, T.; Mabud, Md. A.; Cooks, R. G. Int. I. Mass Spectrom. Ion Processe's 1988, 82, 131-150.

15. Wu, Q; Hanley, L. 1. Pliys. Chem. 1993, 97, 2677-2685.

16. Mabud, Md. A.; Ast, T.; Cooks, R. G. Org. Mass Spectrom. 1987, 22, 418-420.

17. McCormack, A. L.; Somogyi, A.; Dongre, A. R.; Wysocki, V. H. Anal. Chem. 1993, 65, 2859-2872.

18. Cole, R. B.; LeMeillour, S.; Tabet, J.-C. Anal. Chem. 1992, 64, 365-371.

19. Jones, J. L.; Dongre, A. R.; Somogyi, A.; Wysocki, V. H. J. Am. Chem. Soc. 1994, 166, 8268-8369.

20. Despeyroux, D.; Wright, A. D.; Jennings, K. R. Int. I. Mass Spectrom. Ion Processes 1993, 126, 95-99.

21. Beck, R. D.; St. John, P.; Alvarez, M. M.; Diederich, F.; Whetten, R. L. I. Phys. Chem. 1991, 95, 8402-8409.

22. Callahan, J. H.; Somogyi, A.; Wysocki, V. H. Rapid Commun. Mass Spectrom. 1993, 7, 693-699.

23. Williams, E. R.; Henry, K. D.; McLafferty, F. W.; Shabanowitz, J.; Hunt, D. F. I. Am. Soc. Mass Spectrom. 1990, 1, 413-416.
24. ljames, C. F.; Wilkins, C. L. Anal. Chem. 1990, 62, 1295-1299.

25. Lammert, S. A.; Cooks, R. G. I. Am. Soc. Mass Spectrom. 1991, 2, 487-491.

26. Bier, M. E.; Schwartz, J. C.; Schey, K. L.; Cooks, R. G. Int. J. Mass Spectrom. Ion Processes 1990, 103, 1-19.

27. Wysocki, V. H.; Ding, J. M.; Jones, J. L.; Callahan, J. H.; King, F. L. 1. Am. Soc. Mass Spectrom. 1992, 3, 27-32.

28. Aberth, W. Anal. Chem. 1990, 62, 1295-1299.

29. Li, G.; Duhr, A.; Wollnik, H. J. Am. Soc. Mass Spectrom. 1992, 3, 487-492.

30. Wright, A. D.; Despeyroux, D.; Jennings, K. R.; Evans, S.; Riddoch, A. Org. Mass Spectrom. 1992, 27, 525-526.

31. Despeyroux, D.; Wright, A. D.; Jennings, K. R.; Evans, S.; Riddoch, A. Int. I. Mass Spectrom. Ion Processes 1992, 122, 133-141.

32. Chorush, R. A.; Vidavsky, I.; McLafferty, F. W. Org. Mass Spectrom. 1993, 28, 1016-1020.

33. Gross, M. L.; Tomer, K. B.; Cerny, R. L.; Giblin, D. E. In Mass Spectrometry in the Analysis of Large Molecules; McNeal, C. J., Ed.; Wiley: New York, 1986; pp 171-190.

34. Pradeep, T.; Miller, S. A.; Cooks, R. G. I. Am. Soc. Mass Spectrom. 1993, 4, 769-773.

35. Wysocki, V. H.; Kenttamaa, H. I.; Cooks, R. G. Int. I. Mass Spectrom. Ion Processes 1987, 75, 181-208.

36. Dahl, D. A.; Delmore, J. E. SIMION PC/PS2 Version 4.02; Idaho National Engineering Laboratory: EG \& G Idaho, Inc., 1989.

37. Bier, M. E.; Amy, J. W.; Cooks, R. G; Syka, J. E. P.; Ceja, P.; Stafford, G. Int. I. Mass Spectrom. Ion Processes 1987, 77, $31-47$.

38. Pachuta, S. J.; Kenttamaa, H. I.; Sack, T. M.; Cerny, R. L.; Tomer, K. B.; Gross, M. L.; Pachuta, R. R.; Cooks, R. G. I. Am. Chem. Soc. 1988, 110, 657-665.

39. de Ridder, J. J.; Dijkstra, G. Rec. Trav. Chim. 1967, 86, 737.

40. Biemann, K. Biomed. Environ. Mass Spectrom. 1988, 16, 99-111.

41. Jackson, A. T.; Despeyroux, D.; Jennings, K. R. In Proceedings of the 42nd ASMS Conference on Mass Spectrometry and Allied Topics; Chicago, IL, May 29-June 3, 1994; p 463.

42. Alexander, A. J.; Boyd, R. K. Int. I. Mass Spectrom. Ion Processes 1989, 90, 211-240.

43. Yu, W.; Martin, S. A. J. Amt. Soc. Mass Spectrom. 1994, 5, 460-469. 